\title{
Singularity and Uniqueness: Why Is Our Immune System Subject to Psychological and Cognitive Traits?
}

\author{
Amihud Gilead \\ Department of Philosophy, Eshkol Tower, University of Haifa \\ Haifa 3498837, Israel \\ Email: agilead@research.haifa.ac.il
}

January 2014

Abstract. Immunologists use psychological and cognitive terms to describe and explain the behavior of our immune system. Do they use them metaphorically or literally? In this paper I show that on the grounds of some psychophysical assumptions, the uniqueness of each person (or self) as an individual organism necessarily corresponds to the singularity of each person as a psychological subject. On the basis of these assumptions, immunologists, irrespective of their various conceptual frames, are entitled to ascribe psychological and cognitive traits to our immune system and its behavior. Immunologists are allowed to do so because each immune system of any higher, unique individual organism corresponds to psychological traits, which are ascribable only to persons, each of whom is a singular being. This correspondence is necessarily compatible with the psychophysical unity or inseparability. Furthermore, the psychological or cognitive traits pertain to the immune system require no consciousness. In the case of artificial immune systems, in contrast, the application of psychological or cognitive terms is only metaphorical, for each such system is not unique but it is duplicable or replicable. Only the immune system of unique individual organisms that as psychological subjects are singular beings-i.e. persons - can be subject, literally or non-metaphorically, to psychological and cognitive terms.

Keywords:

Immunology, self and nonself; cognitive systems; immunological homunculus; psychological and cognitive terms; psychological and cognitive traits; Polly Matzinger and the danger model; Irun Cohen; Shlomo Breznitz; Thomas Pradeu; Alfred I. Tauber. Panenmentalism; psychophysical assumptions; possibilism; pure possibilities; actualization; singularity; uniqueness; persons as psychological subjects; persons as unique individual organisms. 
The aim of this paper is to demonstrate that immunologists are allowed to use, literally or non-metaphorically, cognitive and psychological terms in describing, understanding, and explaining our immune system.

\section{My Psychophysical Assumptions}

Let us begin with some psychophysical assumptions (hereafter "my psychophysical assumptions"). ${ }^{1}$

Each one of us is a person (self). As a psychological subject, each person is a singular being, namely, he or she is not similar to any other person; he or she is unlike any other person. Singularity is the distinguishing mark of subjectivity, personhood, and selfhood. There is something substantial about each person that makes him or her dissimilar to any other being. As a biological creature, on the other hand, each person (self) is unique, namely, such a creature is not identical to any other biological creature. For instance, as a psychological subject the person called James Joyce was a singular being. In a substantial sense

${ }^{1}$ These assumptions are established, explained, and elaborated in a special possibilist metaphysical theory called "panenmentalism" (Gilead 1999, 2003, 2005, 2009, 2010, 2011, 2013a, and 2013b). Yet, in this paper, they are discussed independently of this metaphysics, which may appear to leave them somewhat unsupported by extensive and detailed arguments. Nevertheless, these assumptions serve here as insights to throw some light on the justification of immunologists in using psychological and cognitive terms while describing and understanding our immune system. Thus, should the reader be persuaded that my psychophysical assumptions indeed throw such light, these assumptions would thus gain the required support to the extent that this essay is concerned. 
there was no other person like James Joyce; whereas as a human being, as a higher organism, James Joyce was unique, namely there was no other human being identical to James Joyce. Hence, James Joyce's brain, immune system, and fingerprints were unique; there was no other human being who could have had Joyce's brain, immune system, or fingerprints. They pertained exclusively to him, yet they shared many properties with other similar organs, systems, or tissues of other human beings. Thus, the brain, immune system, and fingerprints of each human being share some common properties, some similarity with those of other human beings. Uniqueness implies irreplicability or unduplicability. Necessarily, there is no replica or duplicate of my fingerprints, immune system, or brain. My body as a whole is irreplicable or unduplicable. Even if two higher organisms, such as clones or "identical" twins, are supposed to share the same genes, these organisms are not identical or, at least, not strictly identical.

Singularity is what distinguishes us as psychological subjects from any objects. Subjectivity, personhood, and selfhood, as psychological traits, pertain to the category of singularity. Only psychological subjects are singular, whereas some objects can be unique but never singular.

Our psychological singularity has indications. Let me mention two of them. The first is the psychological anomalousness (nomos is "law" in ancient Greek, whereas "anomalous" means "being not subject to laws"): 
our mind, unlike our body, is not subject to the laws of nature, namely, to the laws of physics, chemistry, biochemistry, and biology. There is no physics, chemistry, biochemistry, or biology of the mind. As for psychology, it provides us with nothing that can be considered as a law of nature. Any psychological subject is exempt from such laws. Even if human ways of behavior, attitudes, reactions, and the like show some similarity, order, and structures, still there is no nomic necessity whatever that any of the human subjects should behave or react according to the expectation or predication that such similarity, order, and structures would imply. Human creativity, for instance, is not subject to any psychological law, structure, paradigm, or order and, thus, it can be entirely unexpected or unpredictable. Neither is human creativity subject to any rule. Unlike the psychological, the physical, whether chemical, biochemical, or biological, or strictly physical, is necessarily subject to the laws of nature. No individual body—an organism, for instance-is exempt from these laws. The bodily or the physical, unlike the psychological, is inescapably nomic, namely subject to laws.

The second indication of the psychological singularity is private accessibility. In principle, we have public access to any object, body, or organism. For instance, our brain is publically accessible directly or indirectly (by means of brain imaging technology), whereas there is no such access to our mind. Only I have access to my thoughts, feelings, and 
emotions. If I do not report or "reveal" them to other persons, no other person except me has epistemic access to them. My mind constitutes an inner reality, to which no access from without is possible. As for the future, I see no serious reason to believe that brain imaging, for example, will allow us access to the mind of any person. Obviously, the way I experience, feel, or think about anything is singular, and nobody else can experience, feel, or think what is going on in my mind as I experience, feel, or think it. But private accessibility is much more than that, for it means that nobody else can have epistemic access to my mind. Even if my behavior, expressions, or reactions convey the impression to another person what my psychological state is, that person still has no epistemic access to my mind. Revealing my mind to others is simply a phrase, which does not indicate any possibility for epistemic access from without to my mind.

Our ordinary experience provides us with many solid reasons to consider mind and body as distinct and yet as inseparable. Thus, we have many good reasons to maintain both psychophysical irreducibility

(namely, the mind is irreducible to the body and vice versa) and psychophysical unity, which means that mind and body are inseparable 
and that there is a full correspondence between them. In other words, psychophysical unity means that our body embodies our mind. ${ }^{2}$

Maintaining both these two psychophysical assumptions means that our psychological singularity necessarily corresponds to our biological uniqueness and vice versa. The singularity of the mind is the uniqueness of the body, or the singularity of the mind is embodied as the uniqueness of the body. As singularity is ascribable only to psychological subjects, on the grounds of the psychophysical unity or inseparability, each person as an organism is unique, whereas, as a psychological subject, this person is singular. Psychological singularity, which is anomalous, and biological uniqueness, which is yet nomic (i.e. subject to laws), are inseparable or united. In every case in which an individual organism is unique, namely, unduplicable or irreplicable, psychological traits should be ascribed to it as an embodied psychological subject. The uniqueness of a person as an organism reflects his or her singularity as a psychological subject. Unique organisms are thus subject to psychological and cognitive traits or, in other words, mind necessarily pertains to such organisms to the extent that each one of them is induplicable or irreplicable.

${ }^{2}$ Or, our mind is embodied in our body. In the possibilist terms which panenmentalism endorses, the body is the actuality of our mind, which, in turn, is a singular pure possibility. Hence, the mind is actualized in our body. See the appendix below. 
Because of the psychophysical inseparability or unity, our private accessibility to our mind corresponds to a parallel state concerning our immune system - as we shall see below, the immune system of each one of us has a sort of private or individual accessibility, as it has access only to the body to which this system pertains.

Persons are systematic and coherent complexes of interconnected and interdependent heterogeneous parts, all sharing one and the same psychological reality, privately accessible. Hence, persons can be embodied only as higher, multicellular organisms of a special kind, capable of self-awareness and of relating to other persons, each of whom has a unique immune system. ${ }^{3}$ Each such organism is a unique, irreplicable biological individual. The biological individuality mentioned and discussed in this paper is thus only of persons or "selves" embodied as such organisms. I will return to this issue later below.

All the aforementioned psychophysical assumptions are undoubtedly subject to debates, criticisms, and questioning. My approach to the psychophysical problem is not only a new kind of possibilism, it

${ }^{3}$ For a general definition of organism — "a functionally integrated living thing, highly organized, and made of interdependent parts" - see Pradeu 2013, p. 79. Pradeu "makes clear why taking immunity into account sheds light on the individuation of every multicellular organism" (ibid.). Although most of his paper focuses on the organism as a unified and cohesive multicellular individual, he devotes some of it to show how immunology can be useful also to better understand biological individuals other than multicellular organisms. I, however, do not apply the concept of personal individuality to every multicellular organism, let alone to other kinds of organism (whether unicellular or superorganisms, such as bees, ants, and termites), but only to those who are endowed with highly functional brains that embody self-awareness and the capability of relating to other persons as subjects. 
also opposes externalism, naturalism, and physicalism (or materialism). As metaphysical, such controversies will not end, and each side has its strong supporters as well as its opponents. Recently, Saul Kripke, Frank Jackson, and David Chalmers, to mention only three, have suggested various very solid reasons and arguments against physicalism. Equally, there are some enlightening approaches subscribing to physicalism and suggesting counter-arguments. The same holds true for externalism (like physicalism, there are various kinds of externalism) which I also oppose and whose classical adherents were Quine and Donald Davidson. Of course, there are strong supporters of naturalism as well as no less strong opponents. The issue of psychological private accessibility is also controversial, and naturalist and externalists, such as Donald Davidson, have generally denied its plausibility (as did Wittgenstein in Philosophical Investigations). All the more, the problem of personal identity has been very much with us, beginning with David Hume and going on to Derek Parfit and many others (see Gilead 2008). Finally, psychological anomalousness is also philosophically controversial and yet, undoubtedly, it is perfectly compatible with the singularity of each person as a psychological subject.

I would take issue with any of these controversies, but this paper is not the proper place to defend my metaphysical view as challenging other views. Let me say only this: the reducibility of mind to body, which the 
reductionist physicalism or materialism supports (is there any genuine physicalism that in fact does not support a reduction of the mind to the body?) is entirely incompatible with the widely acknowledged distinction between mind and body, of which all of us, whether physicalistmaterialist or otherwise, should be well aware. Reduction should be considered as unacceptable whenever its price is too high, and any psychophysical reduction ignores major psychophysical differences, varieties, and richness and renders our experience much shallower, poorer, and narrower than it really is. Such reductions inescapably lead to psychophysical poverty, which is susceptible to strong doubts and criticism. As for the psychophysical unity, dualists (to begin with Descartes), Spinoza, or any physicalist, mutatis mutandis, have acknowledged it. We are all well aware of the indisputable fact that there is a very strong connection between our mind and our body despite the differences between them. Finally, as for psychological private accessibility, despite the cliché "a penny for your thoughts," we have no epistemic access to the mind of another person. If we believe otherwise, it is only because of a category mistake - the access that we really have is to the intersubjective (or, in case of intimacy, the interpersonal) implications or reflections of what occurs in the other person's mind, whereas his or her mind per se, intrinsically, is beyond such access. Thus, the access we have to the intersubjective implications or reflections of 
this or that mind is only relational and by no means intrinsic. What is going on in a mind reflects on our intersubjective reality to which we have an epistemic access as we, as psychological subjects, share this reality (it is "inter us"). As I have just said, externalists and naturalists do not accept the idea of private accessibility, but I know of no externalist or naturalist who can offer a penny or even much more for any of my thoughts unless I informed him or her about them (for extensive arguments to defend psychological private accessibility consider Gilead 2003, pp. 43-75; Gilead 2008; Gilead 2011).

\section{Applying Psychological Terms to Immunology: Breznits's Contribution}

It was only very recently (in June 2013), while reading the psychologist Shlomo Breznitz's autobiography (Breznitz 2012, especially pp. $123-$ 132), that I have become acquainted with his inspiring paper, "Immunoalienation: A Behavioral Analysis of the Immune System" (Breznitz 2001). ${ }^{4}$ Having read this paper, it dawned on me that the aforementioned psychophysical assumptions may shed new light on some recent novelties in immunology.

Immunoalienation is the process in which the immune system deviates from its initial status. When the immune system recognizes

${ }^{4}$ Which Breznitz considers as the most important work he has ever made, expecting yet for acknowledgement (Breznitz 2012, p. 132). 
factors of the organism ("self-factors") as alien, autoimmune reaction may occur. The main thesis of Breznitz's paper is about the possible incongruence within the context of the warning immune system of two separate psychological concepts—objective threat, signifying real danger, and threat "as defined by the appraiser" which, in this case, is the immune system (Breznitz 2001, p. 88). Having read Breznitz's paper, I have turned to some more recent developments in immunology. In this paper, I would like to show that the fascinating ideas that Breznitz and some immunologists share can be nicely interpreted in the terms of my psychophysical assumptions. In other words, his paper suggests a novel example in which our immune system, which is a biological entity, is also subject to psychological traits, in addition to chemical and biological properties. Though a great deal of the immune system is subject to physical, chemical, biochemical, or biological properties, it is still equally subject to psychological traits as they are embodied in that system. No wonder that psychological states strongly, sometimes even quite dramatically, reflect on our immunity and the behavior of our immune system.

One of the bold ideas in Breznitz's paper is that no error or mistake is involved in using psychological terms in immunology, for the psychological mechanism of false alarm ("Cry wolf”) describes precisely and explains an undeniable immunological phenomenon. In fact, Breznitz 
demonstrates how psychological mechanism is biologically or immunologically applied, i.e. embodied. In the terms of my psychophysical assumptions, an immunological mechanism, in this case, implements, embodies, a psychological trait or state of a special kind of reaction to threats. Below, I will say more about Breznitz's contribution.

The terms "self," "nonself," or "protected and unprotected self" frequently appear in Breznitz's paper. The use of such terms in immunology raises some philosophical and scientific problems. For instance, even though Anne-Marie Moulin and Alfred I. Tauber consider these terms as metaphors, they did not ignore their indispensability and fruitfulness for immunology (Tauber 1997). Thomas Pradeu points out the ineradicable alleged imprecision involved in these terms while applied to immunology. Such imprecision, he believes, is intolerable insofar as the exact sciences are concerned (Pradeu 2012, p. 129). Moreover, he believes that "the self-nonself theory did not allow for the full understanding of modern immunology's experimental data" (ibid., p. 130).

\section{Matzinger's Danger Model and Its Contribution to the Self- Nonself Controversy; More of the Applicability of Cognitive and Psychological Terms to Immunology and Its Critics}

Indeed, one of the celebrated immunologists of our time has proposed to relinquish the self-nonself terminology in immunology. The abstract of her pioneering article states: 
For many years immunologists have been well served by the viewpoint that the immune system's primary goal is to discriminate between self and non-self. I believe that it is time to change viewpoints and, in this essay, I discuss the possibility that the immune system does not care about self and non-self, that its primary driving force is the need to detect and protect against danger, and that it does not do the job alone, but receives positive and negative communications from an extended network of other bodily tissues. (Matzinger 1994, p. 991)

Pradeu, albeit rejecting the self-nonself theory and claiming that it is not the antigen's “foreignness" (which I associate with Brezntiz's immunoalienation) that causes the immune response, argues that Matzinger's immunological theory is inadequate, too, as the term "danger" is

anthropomorphic at its core, which is problematic for a theory that aims specifically to criticize this very aspect of the self-nonself theory. How could immune cells perceive "danger" as such...? The "danger" is likely to be a projection on the immune system of the immunologist's perception. (Pradeu 2012, p. 208) ${ }^{6}$

${ }^{5}$ Cf. Matzinger 2002a; Matzinger 2007; Matzinger 2011; and Matzinger 2012. Yet, note that Matzinger does not entirely dispense with the term "self," which has a definite meaning in her view: "In the discussion of T cell tolerance that follows, I call 'self' any part of the body, and 'non-self' any part of the rest of the universe" (Matzinger 1994, p. 995). Consider also the reaction of Janeway and others to her model: "self-nonself discrimination is alive and well" (Janeway et al. 1996, p. 519). As Janeway suggests, innate immunity discriminates between infectious nonself and noninfectious self (Janeway 2001). For an earlier critique of Matzinger's model see Vance 2000. Vance argues that "self-nonself discrimination continues to be a 'useful heuristic device' that helps explain diverse immunological phenomena" (Vance 2000, p. 1726). Furthermore, he claims, while the danger theorists, such as Matzinger and Ephraim J. Fuchs, might avoid the word "self," the case appears to be that they "cannot and do not actually discard the concept of "the self"" (ibid.). Hence, he ventures, "danger theorists might secretly agree that self-nonself discrimination does occur on some level" (ibid.).

${ }^{6}$ Vance suggests that what holds true for the self-nonself model holds equally for the danger model, for "the notion of danger curiously fails to live up to the same three criteria used in rejecting the concept of 'self,' namely 1) it isn't well defined, 2) 
Similarly, Tauber warns the reader of the category errors involved in the elusive term of the "immune self." These errors mistake the biological for the psychological or the philosophical, as "self" is a psychological or philosophical term, not a biological one (Tauber 1999). ${ }^{7}$

Tauber acknowledges that in the autoimmune reaction it is the self that "has been violated" (Tauber 1997, p. 228), but, he writes, such cases are exceptional and do not reflect the usual states of the immune systems. Breznitz does not limit his use of the self-nonself terms to such cases, and it is interesting to realize that, while mentioning the term "unprotected self," Breznitz refers to the fact that the immune system recognizes some self elements as alien, which leads to autoimmune reactions (Breznitz 2001, p. 93).

The immunologist Irun Cohen sees no problem in applying the term "recognition" to unconscious entities, as long as discrimination and response are involved in the recognition in discussion (Cohen 2000, pp.

\footnotetext{
it has many exceptions, and 3) it doesn't account for a wide enough range of immunological phenomena" (ibid). Note that "in some cases the immune system may be tuned neither to danger nor strangers. ... The moral is that if the diversity of immune detectors is to be appreciated, it becomes necessary to speak not of a single 'danger' signal, but of multiple 'danger + stranger + other' signals. But if we're going to appreciate the plurality of immunogenic signals, why not discuss the signals directly, and dispense with the monolithic and misleading label of 'danger'?" (ibid., p. 1727). On these grounds, Vance and others "have tried to suggest that, because of its explanatory power, immunologists are right to retain the generalization of 'selfnonself,' despite its flaws" (ibid.).

${ }^{7}$ For a contrary view, defending the use of philosophical-psychological terminology of self-nonself and intentionality in immunology, consult Howes 1998.
} 
125-126). Tauber and Pradeu would probably argue that "recognition" is a psychological term, not a biological or immunological one, which renders such a use of it as a mistake or error. Nevertheless, on the grounds of my psychophysical assumptions, their views may turn out to be considered as wrong, while that of Breznitz (as well as of many immunologists at present, for instance, Irun Cohen and Polly Matzinger, ${ }^{8}$ and previously Frank Macfarlane Burnet, who applied the terms "self" and "non-self" to immunology) can be well explained and justified, notwithstanding the major differences between their immunologist views. Contrary to Matzinger (though without any reference to her), Breznitz suggests “instead of real danger a 'real self' must be defined; and instead of analyzing perceived danger, 'self as defined by the immune system' ought to be analyzed" (Breznitz 2001, p. 98). ${ }^{9}$ The case appears to be that such a view is controversial in the immunologists' community today, yet it can be still defended on quite another basis, as both the self-nonself model and the danger model may synergize to determine the quality and

${ }^{8}$ For the function of recognition in the immune system see Cohen 1992a, p. 442; Cohen 1992b, p. 492; and Matzinger 2007, p. 11. However, Cohen objects to the view that "the immune system deals only with protecting the body against invasion, against the foreign, against danger" (Cohen 2000, p. 192). As he sees it, the immune system, like the brain, is not a transformational, linear, and sequential system; it is rather reactive, on-going, non-linear, and in constant dialogue with its environment and with itself (ibid.). It not only protects the body; it also keeps maintaining it incessantly. Cf. Pradeu 2013.

${ }^{9} \mathrm{Cf}$. "The immune system has a somewhat paranoic bias, that is, everything is a threat. Everything, that is, with the exception of self' (Breznitz 2001, p. 88), which Matzinger would reject entirely.

15 Gilead - Immunology, Singularity, and Uniqueness 
extent of the innate immune responses (Martinon et al. 2009, p. 239 based upon Rock et al. 2005). Indeed, advocating a newer pattern-recognition receptor model, which refers to the potential threat as "very foreign" (Matzinger 2007, p. 11), Matzinger in fact integrates her danger model with the idea of foreignness (or, in Breznitz's term, immunoalienation). In this spirit, she ends her paper with these words:

As we expand our picture of the immune system from an army of lymphocytes patrolling the body for foreigners to an integrated group of communicating tissues, all working to maintain tissue integrity and health, we will necessarily need to include the signals from the non-self organisms that take advantage of that health or that help maintain it. (Matzinger 2007, p. 13) ${ }^{10}$

In these words, Matzinger returns the self-nonself distinction to the realm of update immunology. First of all, the problem lies on the conceptual basis which in turn relies, inter alia, on some psychophysical grounds or assumptions. Moreover, we should attempt as much as possible to save possibilities, and if the synergy of two immunological models, the self-

${ }^{10}$ Cf. Matzinger 2011 and Matzinger 2012. As Alfred Tauber rightly puts it, Matzinger "formulated the immune system as interlocked with every compartment of the body, and thereby regulated in response to 'danger' signals that might arise from any tissue subject to injury or insult. The 'meaning' of immunogenicity, that is, reactivity, in this format is situated within a larger functional framework, for example the sense of 'danger' ensuing from inflammation" (Tauber 2008, p. 234).

Nevertheless, in the spirit of my ideas in this paper, danger and meaning should not be considered as metaphors but as literal concepts concerning our immune system and our organism as a whole. Macfarlane Burnet, who coined the term "the immune self," was the first (already in 1949) to adopt parallels with the psychological self (Tauber 2008, p. 225). Furthermore, immunology becomes part of psycho-neuroimmunology, "which defines immunity as a cognitive activity coordinated with other cognitive systems" (Tauber 2008, p. 235; referring to Ader et al. 2001). 
nonself and the danger model, is proved to be adequate to understand and explain immunological reactions, we should prefer such a synergy also on this basis. I see no real conflict between the two models to the extent that Breznitz's innovation is concerned. On the contrary, they both really help to establish the idea that some biological processes are, in fact, subject to some psychological traits or states.

As early as 1974, Niels K. Jerne applied cognitive terms, such as recognition, learning, and memory, to the immune system (Jerne 1974), which he found analogous to the central nervous system. ${ }^{11}$ Furthermore, his Nobel lecture in physiology or medicine of 1984, referring to Noam Chomsky's generative grammar, made an analogy between linguistics and immunology, between the description of language and that of the immune system (Jerne 1984a). Jerne says: "I find it astonishing that the immune system embodies a degree of complexity which suggests some more or less superficial though striking analogies with human language and that this cognitive system has evolved and functions without assistance of the brain" (Jerne 1984a, p. 223; italics added). To ascribe cognitive functions to the brain is undoubtedly justified, but what allows us to ascribe such functions to the immune system? In what follows I will

${ }^{11}$ Jerne's immunology endorsed the view that "the immune system (like the brain) reflects first ourselves, then produces a reflection of this reflection, and ... subsequently it reflects the outside world ... The mirror images of the outside world, however, do not have permanency in the genome. Every individual must start with self" (Jerne 1984b, pp. 19-20). 
show, on the grounds of my psychophysical assumptions, why we are allowed to apply cognitive and psychological terms to our immune system. In showing this, I will return below to Matzinger's contribution.

\section{A Comment on the "Cognition" and "Individuation" of Bacteria, Social Amoeba, and Social Insects}

Pamela Lyon's biogenic approach, "asking psychological questions as if they were biological questions" (Lyon 2006), is a tantalizing view according to which cognitive capability should be ascribed even to bacteria: "A bacterium may not remember much for long, but it must remember, if only for a few seconds—which may be, relatively speaking, a long time for a microbe" (ibid., which shows the author's pretty sense of humor). ${ }^{12}$ Despite my appreciation and the significant merits of Lyon's biogenic approach, I do not subscribe to this approach but prefer quite a different one instead, considering individuality, uniqueness, and singularity and especially concerning the individuating function of the immune system. Against the background of the current paper and the aforementioned psychophysical assumptions, I would not ascribe cognition, let alone psychological traits, to bacteria unless in a highly metaphorical sense. Undoubtedly, at least to the extent that scientific

${ }^{12} \mathrm{Cf}$ : "recent developments in microbiology undermine standard arguments against bacterial cognition and a closer look at bacterial behavior would reward cognitive scientists" (Lyon 2007, p. 823). 
approaches are concerned, the case appears that we are not allowed to attribute phenomenal qualities (qualia), even in a highly metaphorical sense, to bacteria. As for knowledge and intentions, to ascribe them to bacteria appears to me quite farfetched, as the events in which bacteria are involved should not be considered, under philosophical scrutiny, as actions. Why, according to Lyon's approach, do the reactions of an organism to its environment result in constituting the organism's “cognitive reality"? It is because Lyon defines knowing as "effective action." I can quite easily imagine an effective event, process, change, or even "behavior" (such as atomic, molecular, or mechanical "behavior") which should not be called "action" (unless by question begging) and which is involved with no knowledge or cognition at all. What adapts lower or simpler organisms to their environment would not be knowledge at all. Why should we subject evolutional changes of such organisms to "cognition" or "knowledge"? At least to the extent that these organisms are concerned, evolution implies events or processes, not actions. In general, the survival of the fittest does not necessarily depend on whatsoever action, cognition, knowledge, or intention of the creatures involved. I do not see how a theory of action can be applied to the evolution of simple organisms such as bacteria. 
As for similar interesting contributions, ${ }^{13}$ they should be discussed in a similar vein. Unlike bacteria, "social amoeba," bees, or ants, each higher organism, even those socialized in herds, has an individuality of its own. I understand the concept "higher organism" to apply only to organisms that are substantial individuals, each of which has a unique immune system of its own. We should not consider the herd as an individual unified organism. In contrast, we may consider colonies of bacteria or those of ants, bees, and other social insects as individual unified organisms. Each of such colonies may be analogous to a multicellular individual. We may compare each ant or bee to a cell in a higher organism but we should ascribe non-metaphorical cognitive and psychological terms only to individuals which (or who) are higher organisms embodying cognitive and psychological traits. We should, of course, not ignore ecology, and we should treat our body as an individual ecological system (a conception which rendered possible the first successful kidney transplantation in humans, as Jean Hamburger reported about it). It is clear that in the ecological system of our body bacteria have a role in our immunity (see, for instance, Costello et al. 2012). Nevertheless, none of this diminishes even slightly the substantial

${ }^{13}$ Such as Chen et al. 2007, Ugelvig and Cremer 2007, and Marraffini and Sontheimer 2010 (assuming a discrimination between "self" and "nonself" on p. 186). 
individuality and relative separation of any higher organism and its immune system.

\section{Irun Cohen's Novel Cognitive Paradigm for Immunology}

Challenging the incompleteness of Burnet's clonal selection paradigm, Irun Cohen suggests a fascinating idea, especially from the perspective of my psychophysical assumptions. Cohen suggests a "cognitive paradigm" for immunology (Cohen 1992a), according to which the "immune system must know to focus on particular antigens and how to evaluate their context before it actually encounter the antigens" (ibid., p. 444; italics added). ${ }^{14}$ Cohen defines cognitive paradigms as "founded on the idea that any system which collects and processes information will do its job most efficiently by having an internal representation of its subject. ... in a sense, a cognitive system is a one that knows what it should be looking for ... their internal organization endows them with a kind of intentionality" (Cohen 1992a, p. 443; italics added). Even though "the intentions ... are ours, not nature's" (Cohen 2000, p. 50) and the cognition in discussion does not involve consciousness (ibid., p. 92), the intentionality he ascribed to the immune system is not metaphorical; it

${ }^{14}$ Or, "the healthy immune system usually can be fooled only once. ...The system can learn to interpret context" (Cohen 1992b, p. 491; italics added). 
simply does not reflect any consciousness or teleological assumption (ibid.).

Cognitive systems differ strategically from other systems in the following capabilities: (1) exercising options, namely, making choices or decisions (given that there are also unconscious decisions ${ }^{15}$ ); (2) containing within them internal images of the environment; and (3) selforganizing — using experience to build and update their internal structures and images (Cohen 2000, p. 64). Some of these images are abstract as they are not made of matter but created by processes (ibid., pp. 174-175; for instance the doctor, checking the patient's white blood cell count, consciously diagnoses an infection; similarly, the immune system unconsciously diagnoses or recognizes the state of some tissue as infected). Furthermore, the abovementioned capabilities "in concert make it possible for cognitive creatures to interact with the world in a way that supersedes the confines of evolutionary genetics. Cognition will turn out to be a form of meta-genetic adaptation. Cognition, as it proceeds, creates individuality" (ibid; italics added). ${ }^{16}$ As we will see, on

${ }^{15}$ Cohen 2000, p. 68. Moreover, these decisions are associated with a will: "instead of passively receiving what the environment imposes, the cognitive system exerts its will ... in choosing among alternatives. ... cognitive systems are more resourceful: not only do they choose, they seek" (Cohen 2000, p. 69; italics added). Nevertheless, the choice under discussion is deterministic and "is not dependent on any self-reflective consciousness or mystically free will" (Cohen 2000, p. 182).

${ }^{16}$ Cf.: "Cognition enriches the diversity of existence. ... Cognitive creature, in contrast to non-cognitive creatures [such as bacteria or trees], learn individually and diversify as individuals, and not only as species" (Cohen 2000, p. 93). 
the grounds of my psychophysical assumptions, individuality plays a crucial role in subjecting the immune system to cognitive and psychological traits.

Cohen shows in detail "how antigen selection operates through internal images of infection and of the self (the immunological homunculus). These images in part are encoded in the germ-line, refined in the thymus and primed by mother" (Cohen 1992a, p. 444). ${ }^{17}$ Cohen mentions a threefold set of primary internal images, which constitute "a reference point that define the intentionality of the immune system: which antigens it should seek out and remember" (Cohen 1992b, p. 492; italics added), or "the germ-line elements ... the B cells, and the T cells each analyze different features of the antigenic entity and extract the special information they intend to see ..." (ibid; italics added). ${ }^{18} \mathrm{He}$ also mentions "apparatus of processing and presentation" (Cohen 1992b, p. 494; italics added) and "internal images" allowing "the system to encode

${ }^{17}$ Of course, the immunological homunculus is not some "little man" sitting outside of the immune system and "rules" it; the homunculus is, instead, "the characteristic organization of autoimmunity itself" (Cohen 1992b, p. 493) or "a shorthand designation for the images of the body that self-organize in ... the immune system" (Cohen 2000, p. 205).

${ }^{18}$ Though the information mentioned is not in a strictly psychological sense but rather the one used in Claude Shannon's information theory, consider, yet, the following analogy: "the eyes, organs designed for receiving information, also serve as organs designed for transmitting information [in the cognitive and psychological sense]. ... there is a principle of biological signaling here, ... it working at the molecular level in the immune system" (Cohen 2000, p. 77). And a little bit later, discussing information, Cohen writes: "Meaning is what information does. Indeed, the combination of information [now in a strictly psychological sense] with affect, which generates meaning, gives rise to behavior that feeds back to influence by cognitive creature's world" (ibid., p. 78). 
the essential fragments of the antigenic world to the system specifications and utility" (ibid.). Thus, "contrary to the expectation of clonal selection, the germ-line effectively encodes a primitive internal image of bacteria, viruses, and the context of inflammation" (Cohen 1992b, p. 490). In addition to the term "internal image," Cohen refers to "primitive information arms cells with the capacity to recognize and respond to invaders" (ibid.; italics added). The daring idea of an immunological homunculus is about "an internal image of the self acquired by early recognition of self antigens, both in the thymus and in the periphery" (1992b, p. 492). It is the immune system's representation of the body. Similar to the neurological homunculus, the immunological homunculus contains a "picture of the individual own body" (Cohen 1992a, p. 443). With Cohen, "the individuality of the mind arrives with the individuality of the brain" (Cohen 2000, p. 4), the immune system "defines the material components that make up the self," it is the "guardian of our chemical individuality," and it "establishes the molecular borders of each person" (ibid., p. 5). Note that Cohen's use of the attribute cognitive does not imply consciousness and the term "intentionality" in his works is devoid of personality (Cohen 1992a, p.443), yet it is certainly about individuality and uniqueness. Moreover, the affinity of Cohen's cognitive approach to the immune system and of his approach to the brain is closer to the way in which Gerald Edelman describes the central nervous system 
(Cohen 2000, p. 189). ${ }^{19}$ This affinity, too, supports the application of psychological or cognitive terms to the immune system.

Uri Hershberg, one of the disciples and followers of Irun Cohen, claims in an interview with a philosophical journal that the line between biological systems and cognitive systems is a fake one, as there is no categorical difference between these two kinds of systems; the difference is, instead, of a "mental extension" (Hershberg 2012, p. 29). Thus,

"Even a single cell that needs to act in the world does not do it like a machine. It acts with signals, with meanings. I am not saying that cells have abstract thoughts the way we do. They do not have high cognitive potential. But the way we manage to manipulate those is that we have senses. Even a single cell organism does not really have sensors. They have senses. (Hershberg, ibid.)

As for the term "self," Hershberg admits that it is "a philosophical concept that stands on individuality and what individuality means or how important it is" (ibid., p. 28). Yet, he states, without such a concept immunology cannot do their work, unless immunologists lie to themselves (following ibid, p. 36). The understanding of the immune system implies understanding of biological individuality ${ }^{20}$ or uniqueness.

${ }^{19}$ For a panenmentalist critique of the emergentist psychophysical view of the mind in general and of that of Edelman in particular, consult Gilead 1999, pp. 12, 143, 144, and 161. Cohen, too, is a Darwinian emergentist. Yet, the divergences in psychophysical views should not hinder us from accepting much of Cohen's cognitive conception of the immune system.

${ }^{20}$ Which is a separate important issue in the current philosophy of biology. I do not discuss this issue in the present paper. I refer to the biological individuality, as a multicellular organism's individuality, only to the extent that the immune system is 
Moreover, as the current paper attempts to show, a philosophical view is essential for immunology.

I consider Cohen's cognitive paradigm for immunology as most interesting from the perspective of my psychophysical assumptions, first of all for its use of psychological or cognitive terms literally and not metaphorically. What makes it even more attractive for our analysis is its aim to explain how the immune system "maintains and protects the individual" (Cohen 2000, p. xix). As I have mentioned above, Cohen's conceptual framework "deals with the way the immune system relates to the individual body and defines its individuality" (ibid.; cf. p. 244-245: "tale of cognitive individuality" and "the story of the self"). In the terms of my psychophysical assumptions, the immune system in Cohen's cognitive view relates to the unique identity of each human body which, in these terms, embodies the singularity of a person (at least as far as human beings are concerned). As Cohen's analysis shows, following the sublime Talmudic idea that "Adam was created as a singularity," "each individual fashions a unique world out of his or her unique somatic experience. Therefore, no individual is redundant, ever" (ibid., p. 244). Cohen's analysis has "added the cognitive immune system to the armor of individuality. ... The tale of Adam, like the message of this book, is a a crucial role in the emergence and maintenance of individuality and, thus, in defining biological individuality (Pradeu 2013). 
tale of cognitive individuality" (ibid.). This is beautifully compatible with our independent view of singularity (especially in Gilead 2003 and, to begin with, Gilead 1999).

Contrary to Tauber and others, Breznitz, Cohen, Matzinger, and other immunologists ${ }^{21}$ use the abovementioned indispensible cognitive and psychological terms in a literal sense. In the terms of my psychophysical assumptions, they recognize, in fact though sometimes unknowingly to this or that extent, that our immune system embodies or implements unconscious psychological traits.

Cohen ends his sequel paper thus: "The cognitive paradigm is an immunologist's paradigm of the immune system's paradigm of the molecular world" (Cohen 1992b, p. 494), which means that his paradigm represents the paradigm according to which the immune system consists. Thus, Cohen commits his paradigm to, at least some, correspondence with the immune reality, which means that in fact he considers this paradigm as not only useful but also as true. My view explains this better, I believe, for Cohen does not show what makes the immune reality to correspond to his or other's paradigm. Speaking about usefulness, Cohen's view can be considered as compatible with Tauber's view about "self" and "nonself" as useful metaphors, whereas Cohen, in fact,

${ }^{21}$ Cohen mentions that F. J. Varela, Antonio Coutinho, and others, too, "have called attention to the cognitive properties of recognition, learning, and memory as fundamental to immune behavior" (Cohen 1992a, p. 444). 
suggests much more than that. On the basis of my psychophysical assumptions, he would be entirely allowed to use psychological or cognitive terms literally in analyzing the immune system. Furthermore, Cohen has taught us brilliantly that borrowing ideas and insights from art can contribute to immunology (Cohen 1994).

\section{Tauber's Criticism of Cohen and of Other Immunological Cognitivists}

Tauber refers to Cohen's immunological homunculus and to what he calls Cohen's “cognitive metaphor” (Tauber 1997, pp. 178-182). Tauber ascribes the theories of both Matzinger and Cohen to the "contextualist scheme" (Tauber 1998). According to Tauber, Cohen made a critical theoretical turn regarding the entire notion of selfhood (ibid., p. 466). As I see it, Tauber's recent challenge of the immune self or individuality (Tauber 2012), concerning especially the symbionts hosted in our body and which take part in the immune system, does not affect Cohen's idea of the immunological homunculus in particular and the immune self in general. Given the fact, which Tauber 2012 mentions, that the immune system does not function properly if the symbiotic microbes are not residing, for instance, within the gut, why should the immune self or homunculus not mobilize such organisms for the sake of the body's maintenance and immunity? The hologenome theory of evolution, to 
which Tauber 2012 refers, is possibly adequate for understanding the evolution of coral reefs, for instance, but not necessarily for that of human beings. This may not affect at all the understanding of the human individual organism (or even of the higher vertebrates) as the object of natural selection and of immunology as well. Is the hologenome theory of the evolution of the immune system valid for higher vertebrates in general and for human beings in particular? No human being is simply a "society of cells." Rather, each human being is a singular individual, a self. Contrary to Tauber, I attempt to demonstrate that self, recognition, memory, and learning, as correctly applied to the immune system, are not metaphors at all. Note that Tauber 2012, contrary to Cohen, entirely ignores the unconscious nature of these terms when applied to the immune system.

In 2013, Tauber suggests replacing the representational cognitivist approaches to immunology with "ecological" approaches. Tauber states:

While a representational model has dominated immune theorizing, recent research supports the utility of an "ecological" orientation, which reflects the growing interests in systems biology, where the organism becomes a "node" in an ecological network (Tauber 2012). This approach explores integration of functions (e.g., development, metabolism, immunity) and thereby emphasizes inter-connections, regulative dynamics, and organizational structures of holistic constructs, where individuals become subsumed to relationships of various kinds. (Tauber 2013, p. 241)

In a clear contrast, Cohen, Breznitz, and my philosophical approach consider the individual, especially the human individual, by no means as 
a "node" in an ecological network, which may be more suitable for bacteria, ants, and the like but not for higher organisms, especially human beings. Such individuals are not "subsumed to relationships of various kinds" but, on the contrary — the relationships are subsumed to the individuals. What comes first is the immune system of the individualnot the external ecological system. Human society, per se, has no immune system; each individual owns it, and the first function of this system is to ensure the existence of the individual organism and to maintain its integrity and health. Actions and agency come later; they are secondary. First the system has to perceive and to learn, and only then to act or to decide to remain passive and not to react. Tauber replaces identity by agency, representation and learning — by action, whereas the case appears to be otherwise-our immune system aims primarily at individual being and existence and only secondly at agency. The individuating function of our immune system should not be ignored.

Tauber complains that "notions of selfhood still undergird various contextual theories ...., where a "homunculus" (Cohen 1992b) or even a Bumetian-inspired concept of selfhood ... obscures Jerne's crucial insight that the self-other distinction as a metaphorical extension of human personal identity distorts the character of immune perception" (Tuaber 2013, p. 249, n 9). Again, immunological cognitivists such as Irun Cohen and Shlomo Breznitz make a legitimate literal use of 
psychological and cognitive terms in describing and analyzing our immune system. Moreover, I have not found even a shred of evidence that Cohen relies upon the problematic, even mistaken, analogue of the homunculus in the "Cartesian Theater." On the contrary, the homunculus that Cohen mentions reflects a fruitful neurological concept, to which the immunological homunculus is similar (Cohen 1992a, p. 443), ${ }^{22}$ rather than anything of the "Cartesian homunculus." Such cognitivism does not pertain at all to the "philosophical infrastructure" that guides Cohen and other immunological cognitivists. Cohen never confused the immune system with the scientist as a person. Unlike us, the immune system, as a cognitive system, observes, perceives, reflects, considers, chooses, and decides about anything only unconsciously. This makes a major difference between scientists and the cognitive system as an agency of a self, protecting it and maintaining its integrity and health. Hence, the following criticism by Tauber has no solid ground:

If immune selfhood reflects an underlying conception of a homunculus discerning itself from the other through a cognitive faculty (e.g., Cohen 1992b; 2004), then the same issues confronting current representational philosophies of mind lie latent in contemporary immune theory. Discerning those issues raises a new dimension in the critique of the immune self. Simply, with the invocation of agency, the weakness of the "Cartesian Theater" in the immune setting is apparent: The immune system does not

22 Both the neurological homunculus and the analogue "immunological homunculus" have recently proven to be quite fruitful (see, for instance, Poletaev 2003, 2008, 2012a, and 2012b; Gonzales and Lange 2007; and Zingrone 2010). Following Irun Cohen, Alexander Poletaev coined the term "Immunculus," which is also the name of the scientific institute in Moscow which Poletaev heads.

31 Gilead - Immunology, Singularity, and Uniqueness 
reflect; it perceives without the interposition of an agent reviewing its findings. The scientist observes and constructs the self and its cognition. The phenomenon and the judgment of that phenomenon have distinctive epistemological characteristics that must be maintained. Simply, a sympathetic fallacy is committed when the immune system becomes an immune self. (Tauber 2013, p. 259)

In the next section, I will further discuss Cohen's contribution as well as those of Breznitz and Matzinger.

\section{The Application of My Psychophysical Assumptions to Immunology}

The case appears to be that the self-nonself model is not sufficient for understanding and explaining many of the immune phenomena, which are explained by the danger model in its evolution. Nevertheless, we must not decide between the models. As the immune system is so comprehensive and diverse, it is possible that no model can exhaust it (see, for instance, Vance 2000, pp. 1727-1728). ${ }^{23}$ In any event, this does not mean that selfnonself factors should not be taken into consideration, either. To the extent that Breznitz's novel idea concerning danger and the "Cry wolf" phenomenon is concerned, the danger model is even more fruitful and compatible with the relevant immunological phenomena than the selfnonself model alone. Whichever model one may choose, we still have to

${ }^{23}$ Thus, Vance's concluding suggestion is quite reasonable: "Why not, rather, think of the immune system as a much more diverse collection of mechanisms and processes that have been cobbled together during the course of evolution? If I am right, it will be the details of these mechanisms and their interactions that will ultimately be of interest to immunologists, and not whether they conform to one 'paradigm' or another" (Vance 2000, p. 1728). 
apply terms such as "danger," "foreignness" (or "alienation"), and "self" to the immune system, literally and not in their metaphorical sense. I will now try to establish this literal application on the basis of my psychophysical assumptions.

From this viewpoint, our body, as a biological entity, embodies our mind, which is a psychological, singular being. The singularity of each mind is the singularity of a person, a psychological subject. According to my psychophysical assumptions, we ascribe singularity only to psychological subjects, whereas as organisms, which are subject to the laws of physics, chemistry, and biology, they share some similarities. The singularity of each one of them corresponds to the biological uniqueness of each. ${ }^{24}$ Thus, my genetic signature, my genetic self, is unique as are my finger prints and my immunological system. It is a received view that selfhood is a psychological matter, not simply a physical or biological one, whereas uniqueness is a biological trait of higher vertebrates or mammals. Thus, the question of "alienation" or "foreignness" is crucial when it comes to the biology of higher vertebrates, especially human beings. As our immunological system reflects the uniqueness of each one of us as a biological creature, as a human being, we are allowed to use the precise language of "foreignness" and "alienation," and "self-nonself."

${ }^{24}$ Biological uniqueness is one of the major issues with which Pradeu 2012, too, deals with, raising the question, "What makes a living thing different from all other living things, including those that belong to the same species?" (Pradeu 2012, p. 2). 
There is a strong, necessary, or inseparable connection between our mind and our body and, as a matter of fact, this connection is the psychophysical unity. This unity should be distinguished from identity, as mind and body are not identical or reducible one to the other, although their unity is inseparable. There is, thus, an inseparability of personhood or singularity and biological uniqueness. The immune system of a higher organism guards it against what endangers or threatens its uniqueness. Because the immune system, as part and parcel of our body, implements or embodies some psychological traits as biological actualities, we are allowed, contrary to Tauber, Pradeu, and others, to attribute memory, ${ }^{25}$ recognition, person-nonperson, meaning, ${ }^{26}$ and other psychological traits

${ }^{25}$ Cf.: "'Memory,' whether in the form of differentiated B cells or sensitized T lymphocytes, is an essential component of the immune reaction. ... This 'positive recency effect' (to borrow an expression from the psychology of learning) introduces a systematic bias into the cell population that composes the immune system" (Breznitz 2001, p. 89; italics added). Cf. Cohen: "Memory is another cognitive concept whose mechanism is clearer in the immune system than it is in the brain" (Cohen 2000, p. 186). As for biases, see those concerning the inner images in the cognition systems of our body according to Cohen (2000, pp. 74 and 198).

${ }^{26}$ For instance, Cohen 1992a, p. 442: "To rescue a signal from noise is not sufficient for fitness; we have to know the context in which the signal arrives. Context bestows meaning. The context tells us if the gun we see [cf. ibid.: "what the system can see"] is likely to be a toy or a weapon, if it is theater or murder. A processed peptide presented in the pocket of an MHC molecule may constitute an antigenic epitope for a $\mathrm{T}$ cell, but fitness cannot be promoted without more information. ... Appreciation of context is the beginning of wisdom" (all italics added). With my interpretation, the italicized psychological or cognitive terms are mentioned in this text not as metaphors but literally with the stipulation that they do not involve consciousness and that meaning is simply "the impact of information as an outcome of interaction" (Cohen 2000, p. 98). For more about immune information, meaning, and chemical language see Atlan and Cohen 1998. Note that Cohen discusses a "molecular dialogue" whose character "can be analyzed by exploring five attributes of linguistic communication: abstraction, combinatorial signal, semantics, syntax, and context" (Cohen 2000, p. 183; italics added). The term "abstraction" is in place here, 
to our immune system, not in a metaphoric, ${ }^{27}$ in however useful or fruitful way, but literally, as long as we are aware of the fact that we are discussing individual organisms, each of which is unique, and not psychological subjects each of whom is singular. We are thus discussing psychological traits as biologically embodied under spatiotemporal and causal circumstances and as subject to the laws of physics, chemistry, and biology.

In light of such an explanation, Breznitz's view makes much sense.

It was a brilliant idea to demonstrate that psychological patterns are implemented or embodied by the immune system. I believe that, in the future, immunologists may gain great benefit from learning more and more from psychologists in understanding recognition, memory, commitment, ${ }^{28}$ tolerance, decision, ${ }^{29}$ defense mechanisms, guardianship,

for the immune system reacts to a processed peptide serving as a representation of an infection agent that is not in presence (ibid.). As a cognitive system, "the immune system recognizes not entities but signs of entities. Just as a spoken word is both a physical reality and an abstraction [namely, it is a symbol], a molecule may function as a physical abstraction" (ibid'.). See more about the immune semantic and syntax, language and dialogue (ibid., pp. 184-185). In sum, Cohen believes that "the immune language might share strategic structures with natural language worthy of study; they both are concerned with generating meaning out of information" (Cohen 2000, p. 185). Cf. Jerne 1984a.

${ }^{27}$ Unlike the following, concerning the danger theory: "Those who insist on experimental verification miss the point of these theories, which are essentially metaphorical generalizations, far abstracted from the gritty but testable details of immunity" (Vance 2000, p. 1727). Endorsing the idea of saving possibilities, I prefer instead Carolyn Strange's view as, while referring to Matzinger's novelty, she reminds the reader: "Upon breaking free of old assumptions, researchers can begin to consider new possibilities that had been quite literally unthinkable. When dogma predicts that an experiment would not work, it rarely is performed" (Strange 1995, p. $665)$.

${ }^{28}$ Which Breznitz 2001, p. 90 mentions. 
protection, treating and mistreating threats and danger, containing or holding, associating, ${ }^{30}$ responding or answering, ${ }^{31}$ education, ${ }^{32}$ dialogue or conversation, ${ }^{33}$ and the like, all of which have served immunologists quite fruitfully, not as merely metaphors, however useful and even indispensable. Such terms shed light on immunological phenomena. Such is the case because the identity of some of the biological embodiments or implementations taking part in our body rests inescapably on the psychological, on the singularity of each one of us.

Our era is facing an imminent danger to the independence of psychology, which many brain scientists as well as psychologists attempt to reduce to the research into the functions of the brain. This most

${ }^{29}$ Breznitz refers to “a 'decision' must be made whether to effect an immune response against them or to tolerate them. The most typical instance of the need to deal with what psychologists call ambivalence is in the context of an immunological cross-reaction. ... In this respect, not unlike in the case of the psychology of conflict, subsequent reactions follow prior commitments" (Breznitz 2001, p. 91). It appears that Breznitz hesitates between his bold application of psychological terms to immunology and the dogmatic reluctance to do so, for there are cases in which he does not mark psychological terms with inverted commas (in this citation, ambivalence, tolerance, and commitments), whereas in other cases he uses them (in this citation, "decision;" and, while Clarke and Playfair mention the term "decision" with no inverted commas, in the citation from their paper, Breznitz, nevertheless, adds them in his comment to the cited term). As far as I can see, he is not consistent in this matter. From our viewpoint, he is consistently allowed to dispense with the inverted commas in each of these cases. So does Matzinger (except for "self" and "nonself") by and large in her papers known to me.

${ }^{30} \mathrm{Cf}$., for instance: "If we give the body a molecule at the time that something else has caused damage, the immune system will associate that new molecule with the (unassociated) damage, and respond to it" (Matzinger 2012, p. 311; italics added). Cf. "cognitive systems make associations" (Cohen 2000, p. 69).

31 "The first question the immune system needs to ask when faced with something” is “'Do I respond or not?' However, once you respond, there is a second question to ask, 'What kind of response do I make?' ... How does the immune system determine what kind of response it is going to make?" (ibid., p. 313; italics added).

${ }^{32}$ Matzinger 2012, p. 316.

${ }^{33}$ Ibid., p. 317. 
dangerous trend may endanger not only the existence of psychology as a substantive, independent science, irreducible to biology, neuroscience, computer science, and the like, but, even more, it may endanger biology as a wide-ranging and promising science and render it less abundant and much less promising. Psychology may save many fruitful possibilities for biology. Breznitz has made a pioneering step toward this aim, but so far this step appears to have no major continuation. It is an annoying symptom of the intellectual poverty of our era. Applying the "psychological properties of warning systems, and particularly problems of credibility and false alarms" to the "lawfulness discovered in biological warning systems" (Breznitz 2001, pp. 86-87) is a most promising and fruitful idea. Curiously enough, the danger immunologists, such as Matzinger, ${ }^{34}$ often discuss the stress of cells and tissues, ${ }^{35}$ whereas though Breznitz is a celebrated specialist in the psychological research of the phenomenon of stress, he does not mention the term

${ }^{34}$ The immune system selects as dangerous anything that causes cell stress or necrotic cell death (Matzinger 1994, pp. 1023 and 1037). Cf. Vance 2000, p. 1727. Note that "while it might be agreed that the immune system can sense endogenous signs of distress (danger), the question is whether immunology should be limited, a priori, to the study of these endogenous signs-especially as the molecular mechanisms that the immune system uses to detect 'strangers' is becoming increasingly understood" (Vence 2000, ibid.). This may make Breznitz's immunoalienation even more attractive. After one year of the publication of his paper, Matzinger had published a very short outline of her novel theory in the very same journal (Matzinger 2002b)!

${ }^{35}$ Cohen's immunological theory explains how the immune system detects and focuses on self stress proteins and reacts to them (Cohen 2007, p. 571). Stress proteins "can provide the ... immune system with crucial information about the local state (stressed or un-stressed) of the tissue" (ibid.). Breznitz's psychological theory of stress may shed more light on this important aspect of the immune system. 
"stress" or "distress" in his paper on immunoalienation. Nevertheless, he explicitly applies his false alarm theory ("Cry wolf") to immunology. The association between Matzinger's danger theory and the false alarm concerning the immune system has been suggested in the literature, ${ }^{36}$ though not by Matzinger herself. The danger theory has an interesting application to artificial immune systems in computer science and engineering, also associated with the problem of false alarm (Dasgupta et al. 2010).

If Breznitz were familiar with Matzinger's theory, according to which not only the immune system takes part in protecting our body against danger and threats but our tissues and members also take part in it, the following problem would have been solved according to his own theory:

From the viewpoint of the behavioral analysis of warning systems, a central weakness of the immune system stems from the fact that it has a virtual monopoly over the protection of the organism of which it is a part. This precludes corrective feedback about its effectiveness. The history of human warning systems abounds in examples in which the absence of extrinsic information (that is, from sources other than the warning system itself) can lead to major mistakes. The monopoly over information ensures the unchecked growth of biases. (Breznitz 2001, p. 92)

In Matzinger's theory, there is always room enough for extrinsic information, which the immune system processes. Thus, much like in

${ }^{36}$ For instance, Pittman and Kubes 2013, p. 320; and Mills 2012. 
human behavior, in cases where there is extrinsic information, the chance of making mistakes, especially serious ones, is minimized. Were human intelligence agencies as sophisticated as our immune system, they would undoubtedly have made fewer mistakes in processing information. No act of espionage-however sophisticated — can do the job as efficiently as our immune system.

As for Breznitz's application of the psychological distinction between minimal and difference thresholds of the immune system, it may be found useful in understanding, within the danger model, why monoclonal processes (whose evolvement begins with one single cell), such as monoclonal tumors or pregnancy, are not attacked by our immune system (Breznitz 2001, p. 94): because of subthreshold kinetics the slower rate of growth increases the chance of avoiding detection by the immune system. ${ }^{37}$

The false alarm phenomenon, which Breznitz explored as a psychologist and to which he devoted a whole book (Breznitz 1984), is not valid for fully automated warning systems; it is rather valid for an entirely different kind of alarm systems in which decision-making or the evaluation of alternatives and learning from previous experiences take

${ }^{37}$ Cf. Matzinger's explanation: “An early growing tumor is a healthy tissue not sending alarm signals, and therefore is constantly inducing tolerance to itself" (Matzinger 2012, p. 316). 
place (Breznitz 2001, p. 87). ${ }^{38}$ Such, obviously, is my psychological

alarm system. Only in such, non-fully automated warning systems, may

the phenomenon of false alarm based on previous experiences occur. The gist of the matter is that Breznitz finds evidence for the existence of the false alarm phenomenon not only in human behavior but also in the behavior of the immune system (which is well compatible with Matzinger's danger model). In this system, too, the "false alarm phenomenon" is not a metaphor but its sense is fully literal. In other words, or in the terms of my psychophysical assumptions, our immune system implements or embodies processes of decision-making, evaluations of alternatives, and learning. The difference between this biological embodiment and that of our similar psychological processes of conscious decision-making, choosing and deciding between alternatives, and of learning is quite clear. Our immune system needs no consciousness to perform its tasks. While our immune system makes some choices and learns from previous experience, there is no deliberation which is subject to consciousness. ${ }^{39}$ The phenomena of

${ }^{38} \mathrm{Cf}$. "T cells and B cells are central to the cognitive enterprise because they can learn from experience" (Cohen 2000, p. 107).

${ }^{39}$ Yet consider the following as regards unconscious deliberation in the immune system: "Co-respondence can even help some of the logic of immune anatomy. Lymph nodes can be viewed as the courts where immune agents can gather to present their findings for communal co-respondence in camera, secluded from distractions in the tissue arena of action. Once their mutual deliberations lead to a joint immune decision, the agent can exit the lymph node to return to the blood for delivery of their verdict to the tissues. Lymph nodes are not only district offices ..., 
detection, recognition, processing information, and alienation are also literally valid for our immune system to the extent that none of them requires consciousness. This holds true for alarms, threats, signals, memory, inter-cell communication, stress, and distress, as these terms are used in immunology.

To show that the psychological terms and the psychological traits that have been ascribed above to the immune system cannot be ascribed to inanimate systems, such as computers or any software (which are fully automated systems), ${ }^{40}$ we have to refer again to the issues of biological identity, uniqueness, and individuation to the extent that the immune system is concerned. No immune system of a higher individual multicellular organism can be duplicated or replicated, for each such a system is unique, bearing its single identity. Unconscious decisions, recognition, a sense of danger or threat, and all the other abovementioned psychological traits are applicable to the immune system of higher

they can function as local, ad hoc, brains" (Cohen 2000, pp. 161-162). Here, too, he makes some analogies between the brain and the immune system. When it comes to cognitive and psychological terms, these analogies make much sense, for undoubtedly the brain embodies psychological traits and states. The difference is that while the brain can also embody conscious psychological traits, the immune system cannot do so.

${ }^{40}$ Even though Cohen argues that the immune system uses a computational strategy to carry out its function and that reframing our view of this system in computational terms is worth our while, he, nevertheless, clearly emphasizes that there is "a fundamental difference between the computations performed by the immune system and those done by a computer. A Turing machine is not modified by either its input or its output; it simply functions according to a preset program. The immune system of every individual, in contrast to a Turing machine, is selforganizing; it learns from experience; it has memory" (Cohen 2007, p. 570). Cf. Hershberg 2012, p. 29. 
organisms but never to inanimate beings, none of which is unique, irreplicable, or unduplicable. Any hardware or software is replicable or duplicable; no hardware or software is unique in principle. It is the nature of such devices that they are duplicable or replicable. In contrast, my finger prints are unique and there cannot be any other person who has the same finger prints. My immune system is unique; nobody else can share it with me. This holds true also for so-called "identical" twins.

As for the individuation function that Pardeu ascribes to any immune system (Pradeu 2013, pp. 90-92), including that of unicellular "organisms" and "superorganisms," any biological individuality ascribed to such a system does not entail subjecting it literally, and not only in a metaphorical sense, to psychological traits or to cognitive and psychological terms. Only the immune system of an organism that is a biological embodiment of a person, namely, of a singular subject, is allowed to be subject non-metaphorically but rather literally to psychological traits and to cognitive and psychological terms.

Psychological subjects, each of which is singular, can be thus embodied only as organisms that have a higher biological individuality and identity. When we ascribe psychological traits to inanimate beings, such as computers, we are dealing only with metaphors, not with the literal sense of these terms. Thus, we ascribe "(artificial) intelligence," “memory," "information processing," "thinking," "decisions," or 
"intentions" to computers metaphorically only. We borrow the terms from the concepts pertaining to our mind and metaphorically apply them to human-made machines. The intelligence, memory, meaning, thinking, deciding, and intending in the case of these machines pertain literally only to the human beings who planned and produced the hardware or the software. Still, consciousness is not a necessary condition for applying these terms literally. Thus, though our immune system is not a conscious system, it implements and performs unconscious psychological processes, and we are entitled to ascribe to it not only beauty but also admirable wisdom.

I have argued above that psychological subjects, who are singular beings, are embodied as organisms, each one of which has a unique identity. When it comes to our immune system, it is inevitable to emphasize that biological uniqueness and identity are indispensable, hence we cannot dispense with the self-nonself distinction. The selfnonself distinction (in any of its variations, including Cohen's immunological homunculus) is inevitable in understanding and explaining our immune processes. Insofar as we must apply to them the abovementioned cognitive or psychological terms and psychological traits, the distinction self-nonself should be valid for the immune system. Of course, the danger theory is equally indispensable, but it is not sufficient to justify the claim that only some biological embodiments 
which have a biological individuality and uniqueness can be of singular, psychological subjects, which require the self-nonself distinction. Note that Matzinger, although following consistently the damage theory/model, does not dispense with the self-nonself distinction entirely. After all, the damage in question is of a multicellular individual creature not of a collective of whatsoever kind. There is no immune system of a species or a genus. The immune system protects biological individuals. ${ }^{41}$ When it comes to human individuals the term "self" is entirely in place. The singularity of each mind implies private accessibility, which means that each person has exclusive access, first of all epistemic, to his or her mind (Gilead 2003, pp. 43-75; Gilead 2008; and Gilead 2011). No one else, whether omniscient or not, has any access to any other mind. I have no access to the thoughts, emotions, feelings, sensations, and volitions of any other person. Equally, my immune system cannot perceive and respond to the signals pertaining or addressed to the immune system of other person. Following the approach that Irun Cohen suggests, my immune system can defend and maintain only my body; it has no access

${ }^{41}$ For a contrary example see Cohen 2000, pp. 251-252, as there are circumstances in which the immune system kills the individual for the benefit of the species. How is this compatible with Cohen's leitmotiv that the story of the immune system is the "tale of cognitive individuality" and "the story of the self"? He himself raises the question and tries to answer it: "Evolution is supposed to work on individual survival ..., not on group survival. How could a species have ever evolved an immune program to kill the individual? ... Just note that the immune system is a contractor of apoptosis for sick cells ..., and sick individual, too, when the need arises" (Cohen 2000, p. 252). Nevertheless, sick cells are not individuals, at least not in the higher or complex sense that human beings undoubtedly are. As for the issue of social immunity, consider also the papers mentioned in footnote 13 above. 
to the body of any other person. ${ }^{42}$ The psychological accessibility and the immune accessibility are thus entirely compatible and they are, like the psychophysical unity as a whole, inseparable. Contrary to the view of Tauber and others, at least the borders of the self, physically and psychologically, are well defined, and at least from this respect, the immune self is quite clear and sound. Moreover, the private accessibility concerning our mind, on the one hand, and our immune system, on the other, is more than enough to safeguard the idea of the self in general and the immune self in particular. ${ }^{43}$

\section{Conclusions}

On the grounds of my psychophysical assumptions, the unity or inseparability of the self, as a psychological subject, and the unique immune system of each individual, the immune self, is well kept.

${ }^{42}$ Only the case of the fetus is different to some extent, and the immune system of the mother takes part in its immunity. Yet this does not allow her access to the mind of the fetus as they are two distinct psychological subjects. Furthermore, breastfeeding shares, as does blood transfusion to some extent, some of the antibodies of one person with the other but all such antibodies are mobilized to the service of the unique immune system of the other, receiving individual.

${ }^{43}$ This view may shed a surprising light on the following ideas of Pradeu concerning the immune system: "The immune system offers a principle of inclusion ..., because it establishes what is rejected and what is not rejected by an organism. In so doing, the immune system determines which constituents stick together and thus are parts of one and the same organism. In addition to this exclusion-inclusion mechanism, the immune system is truly 'systemic' in the sense that ... it exerts its activity everywhere in the organism, insuring the unity and the cohesiveness of the organism as a whole" (Pradeu 2013, pp. 79-80). 
One of the lessons that this paper suggests is that immunologists may benefit significantly from borrowing insights and ideas suggested by metaphysicians, philosophers, psychologists, linguists, cognitive scientists, and artists, and vice versa.

I have demonstrated above that applying psychological traits and cognitive or psychological terms literally to our immune system, in any of the different immunological studies discussed above, is perfectly legitimate, at least in the light of my psychophysical assumptions.

\section{Appendix. Immunology and Panenmentalism: Why Does Our Immune System Actualize Psychical and Cognitive Possibilities?}

Let me put my approach to the above in panenmentalist terms.

Panenmentalism is a metaphysical theory about individual pure possibilities and their actualities (Gilead 1999, 2003, 2005, 2009, 2010, 2011, 2013a, and 2013b). Regardless or independent of any actual existence and of any spatiotemporal and causal conditions, each individual existent is a pure possibility. Such, for instance, is the existence of numbers or geometrical figures as long as they are not considered as actual existents, namely, actualities, or as abstractions from actual-physical reality. Numbers and geometrical figures are thus mathematical individual pure possibilities. 
The combination actual-physical requires some explanation.

Panenmentalism begins its investigation in dealing with the psychophysical problem. It offers a novel way of dealing with this timehonored problem — the body, as a physical entity, is the actuality of the psychical pure possibility that is the mind. In this way, the psychophysical unity and the psychophysical irreducibility (namely, the mind is irreducible to the body and vice versa) are both well kept. Furthermore, the conditions, especially the spatiotemporal and causal ones, to which the actual and the physical are subject, are the same. Hence, the only possible actualization of any pure possibility, psychical or otherwise, is physical. By "physical” I mean strictly physical, chemical, biochemical, or biological.

Each individual actual existent—actuality—is an actualization of an individual pure possibility. Such an individual pure possibility serves as the identity of the relevant actuality, thus it is the pure possibilityidentity of that actuality. Indeed, there is no entity without identity, yet, unlike Quine's precept (Quine 1969, p. 23), the identity in discussion is individual pure possibility. No two individual pure possibilities can be identical otherwise they would have been one and not two. As exempt from any spatiotemporality, individual pure possibilities are inescapably subject to the metaphysical principle of the identity of the indiscernibles. Individual pure possibilities, however, can be similar unless they are 
psychical possibilities pertaining to different psychical subjects, i.e., persons. Each psychical possibility is singular, namely, it cannot be similar to the psychical possibilities of other persons. Such is the nature only of psychical possibilities, which distinguishes them from all the other individual pure possibilities. The psychical is a singular section of the purely possible as a whole. Panenmentalism endorses psychical anomalousness, namely, the psychical is anomalous-it is not subject to laws - whereas the actual-physical is necessarily subject to the laws of nature.

The singularity of each person, as a psychical subject, is a central idea in panenmentalism (to begin with Gilead 1999 and as elaborated in Gilead 2003). Since the actualization of any pure possibility, singular or not, is subject to some similarity according to the laws of physics, chemistry, biochemistry, and biology, psychical singularity is actualized merely as physical uniqueness. For instance, each human being is a singular person, sharing no similarity with any other person, whereas each person has, for instance, a unique brain, a unique immune system, unique finger prints, and the like. Any finger prints share some common properties with the finger prints of other persons, but each person has unique finger prints, which pertain to him or her alone. The same holds for our immune system — the immune systems of all human beings share some similarities, yet each human being has a unique immune system that 
cannot be shared with other human beings, even if the other human being is an "identical" twin.

Persons are systematic and coherent complexes of interconnected and interdependent heterogeneous parts, all sharing one and the same psychical reality, privately accessible. Hence, persons can be actualized only as higher, multicellular organisms of a special kind, capable of selfawareness and of relating to other persons, each of whom has a unique immune system. Each such organism is a unique, irreplicable biological individual. The biological individuality mentioned and discussed in this paper is thus only of persons or "selves" actualized as such organisms. 


\section{References}

Ader, R., Felten, D. L., and Cohen, N. (eds). (2001), Psychoneuroimmunology (San Diego: Academic Press).

Atlan, Henri and Cohen, Irun R. (1998) "Immune Information, Self-

Organization, and Meaning," International Immunology 10, pp. 711-717.

Breznitz, Shlomo (1984). Cry Wolf: The Psychology of False Alarms

(Hillsdale, NJ: Laurence Erlbaum Associates).

Breznitz, Shlomo (2001). "Immunoalienation: A Behavioral Analysis of the

Immune System," Annals of the New York Academy of Science 935, pp. 86-97. DOI:

10.1111/j.1749-6632.2001.tb03473.x

Breznitz, Shlomo (2012) The Tapestry of Life (in Hebrew) (Tel-Aviv:

Hakibbutz Hameuchad).

Chen, Guokai et al. (2007) "Immune-Like Phagocyte Activity in the Social

Amoeba," Science 317, pp. 678-681.

Cohen, Irun R. (1992a) "The Cognitive Principle Challenges Clonal

Selection," Immunology Today 13, pp. 441-444.

Cohen, Irun R. (1992b) “The Cognitive Paradigm and Immunological

Homunculus," Immunology Today 13, pp. 490-494.

Cohen, Irun R. (1994) “Kadishman's Tree, Escher's Angels, and the

Immunological Homunculus." In Coutinho, A. and Kazatchkine, M. D. (eds).

Autoimmunity: Physiology and Disease (New York: Wiley), pp. 7-18.

Cohen, Irun R. (2000) Tending Adam's Garden: Evolving the Cognitive

Immune Self (San Diego: Academic Press).

Cohen, Irun R. (2007). "Real and Artificial Immune Systems: Computing the

State of the Body," Nature Reviews/Immunology 7, pp. 569-570.

Costello, Elizabeth K. et al. (2012) "The Application of Ecological Theory

Toward an Understanding of the Human Microbiome," Science 336, pp. 1255-1262.

Dasgupta, D. Yu, D., and Nino, F. (2010) "Recent Advances in Artificial

Immune Systems: Models and Applications, Applied Soft Computing Journal.

DOI:10.1016/j.asoc.2010.08.024

Gilead, Amihud (1999). Saving Possibilities: An Essay in Philosophical

Psychology (Amsterdam \& Atlanta: Rodopi - Value Inquiry Book Series, Vol. 80).

Gilead, Amihud (2003). Singularity and Other Possibilities: Panenmentalist

Novelties (Amsterdam \& New York: Rodopi - Value Inquiry Book Series, Vol. 139).

Gilead, Amihud (2005). "A Possibilist Metaphysical Reconsideration of the

Identity of Indiscernibles and Free Will," Metaphysica 6, pp. 25-51.

Gilead, Amihud (2008) "A Humean Argument For Personal Identity,"

Metaphysica 9, pp. 1-16.

Gilead, Amihud (2009). Necessity and Truthful Fictions: Panenmentalist

Observations (Amsterdam \& New York: Rodopi - Value Inquiry Book Series, vol.

202).

Gilead, Amihud (2010). "Actualist Fallacies, From Fax Technology to Lunar

Journeys," Philosophy and Literature 34:1, pp. 173-187.

Gilead, Amihud (2011). The Privacy of the Psychological (Amsterdam \& New

York: Rodopi - Value Inquiry Book Series, vol. 233).

Gilead, Amihud (2013a). "Shechtman's Three Question Marks: Possibility,

Impossibility, and Quasicrystals," Foundations of Chemistry 15, pp. 209-224. DOI:

10.1007/s10698-012-9156-y 
Gilead, Amihud (2013b). "Pure Possibilities and Some Striking Scientific Discoveries," Foundations of Chemistry. DOI: 10.1007/s10698-013-9190-4

Gonzales, G. and Lange, A. (2007) "Cancer Vaccine for Hormone/Growth Factor Immune Deprivation: A Feasible Approach for Cancer Treatment," Current Cancer Drug Targets 7, pp. 229-241.

Hershberg, Uri (2012). "Life as a Meshwork of Selves: Interview with Uri Hershberg," Avant 3, pp. 26-36.

Howes, Moira (1998). "The Self of Philosophy and the Self of Immunology," Perspectives in Biology and Medicine 42, pp. $118 \mathrm{ff}$.

Janeway, Ch. A., Goodnow, Ch. C., and Medzhitov, R. (1996)

"Immunological Tolerance: Danger-Pathogen on the Premises!," Current Biology 6, pp. 519-522.

Janeway, Ch. A. (2001). "How the Immune System Works to Protect the Host from Infection: A Personal View," Proceedings of the National Academy of Science of the USA 98, pp. 7461-7468.

Jerne, Niels K. (1974) "Towards a Network Theory of the Immune System," Annals of Institute Pasteur/Immunology 125C, pp. 373-389.

Jerne, Niels K. (1984a) “The Generative Grammar of the Immune System.” In Lindsten, Jan (ed.). Nobel Lectures: Physiology or Medicine 1981-1990 (Singapore: World Scientific, 1993), pp. 211-225.

Jerne, Niels K. (1984b) "Idiotypic Networks and Other Preconceived Ideas," Immunological Review 79, pp. 5-25.

Lyon, Pamela (2005). "The Biogenic Approach to Cognition," Cognitive Processing 7, pp. 11-29. DOI 10.1007/s10339-005-0016-8

Lyon, Pamela (2007) "From Quorum to Cooperation: Lessons from Bacterial Sociality for Evolutionary Theory," Studies in History and Philosophy of Biological and Biomedical Sciences 38, pp. 820-833.

Marraffini, Luciano A. and Sontheimer (2010) "CRISPR Interference: RNADirected Adaptive Immunity in Bacteria and Archaea," Nature Reviews Genetics 11, pp. 181-190.

Martinon, Fabio et al. (2009) "The Inflammasomes: Guardians of the Body," Annu. Rev. Immunol. 26, pp. 231-246.

Matzinger, Polly (1994). "Tolerance, Danger, and the Extended Family,"

Annu. Rev. Immunol. 12, pp. 991-1045.

Matzinger, Polly (2002a). "The Danger Model: A Renewed Sense of Self," Science 12, pp. 301-305.

Matzinger, Polly (2002b) "An Innate Sense of Danger," Annals of the New York Academy of Science 961, pp. 341-342.

Matzinger, Polly (2007). "Friendly and Dangerous Signals: Is the Tissue in Control? Nature Immunology 8, pp. 11-13.

Matzinger, Polly (2011) "Tissue-Based Class Control: The Other Side of Tolerance," Nature Reviews/Immunology 11, pp. 221-230.

Matzinger, Polly (2012) “The Evolution of the Danger Theory," Expert. Rev. Clin. Immunol. 8, pp. 311-317.

Mills, Charles D. (2012). "M1 and M2 Macrophages: Oracles of Health and Disease," Critical Reviews in Immunology 32, pp. 463-488.

Pittman, K. and Kubes, P. (2013) "Damage-Associated Molecular Patterns Control Neutrophil Recruitment," Journal of Innate Immunity 5, pp. 315-323. 
Poletaev, A. B. and Osipenko L. (2003) General Network of Natural Autoantibodies as Immunological Homunculus (Immunculus)," Autoimmunity Rev 2, pp.264-271.

Poletaev, A. B. et al. (2008) "Integrating Immunity: The Immunculus and Self-Raactivity," Journal of Autoimmunity 30, pp. 68-73.

Poletaev, A. B. et al (2012a), Immunophysiology versus Immunopathology: Natural Autoimmunity in Human Health., Pathophysiology. http://dx.doi.org/10.1016/j.pathophys.2012.07.003

Poletaev, Alexander B. (2012b). "Maternal Immunity, Pregnancy, and Child's Health." Chapter 3 in Sifakis, S. (ed.), From Preconception to Postpartum (Rijeka, Cro. and Shanghai: InTech), pp. 42- 56. http://www.intechopen.com/books/frompreconception-to-postpartum/maternal-immunity-pregnancy-and-childs-health

Pradeu, Thomas (2012) The Limits of the Self: Immunology and Biological Identity (Oxford: Oxford University Press).

Pradeu, Thomas (2013) "Immunity and the Emergence of Individuality." In Buchard, F. and Huneman, Ph. (eds.), From Groups to Individuals: Evolution and Emerging Individuality (Cambridge, MA.: MIT Press), pp. 77-96.

Quine, Willard van Orman (1969) Ontological Relativity and Other Essays (New York: Columbia University Press).

Rock, K. L. et al. (2005) "Natural Endogenous Adjuvants," Springer Semin. Immunopathol. 26, pp. 231-246. 668.

Strange, Carolyn (1995). "Rethinking Immunity," BioScience 45, pp. 663-

Tauber, Alfred I. (1997). The Immune Self: Theory or Metaphor? (Cambridge: Cambridge University Press).

Tauber, Alfred I. (1998). "Conceptual Shifts in Immunology: Comments on the 'Two-Way Paradigm'," Theoretical Medicine and Bioethics 19, pp. 457-473.

Tauber, Alfred I. (1999), "The Elusive Immune Self: A Case of Category Errors," Perspectives in Biology and Medicine 42, pp. $459 \mathrm{ff}$.

Tauber, Alfred I. (2008). "The Immune System and Its Ecology," Philosophy of Science 75, pp. 224-245.

Tauber, Alfred I. (2012) "The Biological Notion of Self and Non-self," The Stanford Encyclopedia of Philosophy (Summer 2012 Edition), Zalta, E. N. (ed.), URL $=<$ http://plato.stanford.edu/archives/sum2012/entries/biology-self/ $>$.

Tauber, Alfred I. (2013) "Immunology's Theories of Cognition," History and Philosophy of the Life Sciences 35, pp. 239-264.

Ugelvig, Line V. and Cremer, Sylvia (2007) "Social Prophylaxis: Group Interaction Promotes Collective Immunity in Ant Colonies," Current Biology 17, pp. 1967-1971.

Vance, Russell E. (2000) "Cutting Edge Commentary: A Copernican Evolution? Doubts about the Danger Theory," The Journal of Immunology 165, pp. $1725-1728$.

Zingrone, Nancy L. et al. (2010) "Out-of-Body Experiences and Physical Body Activity and Posture: Responses from a Survey Conducted in Scotland" The Journal of Nervous and Mental Disease 198, pp. 163-165. 